\title{
The heterozygous mutation of c.346-1G>A in SOHLH1 gene is irrelevant to nonobstructive azoospermia
}

\author{
Mohan Liu ${ }^{1}$, Yihong Yang ${ }^{1}$, Yaqian $\mathrm{Li}^{1}$, Su-Ren $\mathrm{Chen}^{2}$, and Ying Shen ${ }^{1}$ \\ ${ }^{1}$ Sichuan University \\ ${ }^{2}$ Beijing Normal University
}

October 11, 2020

\begin{abstract}
Nonobstructive azoospermia (NOA) is an important cause of male infertility, and the genetic pathogenesis is still incompletely understood. The previous study reported that heterozygous mutation of c.346-1G > A in SOHLH1 gene was identified in two NOA patients. However, in our research, this heterozygous mutation was confirmed in a Chinese infertile patient who was suffered from teratozoospermia, and intriguingly, a homozygous mutation of c.346-1G>A in SOHLH1 gene was detected in another patient with severe oligozoospermia. Additionally, we correlated the good prognosis of intracytoplasmic sperm injection (ICSI) in the patient carrying the heterozygous mutation of c.346-1G $>$ A in SOHLH1 gene. Thus, we suggested that the heterozygous mutation of c.346-1G>A in SOHLH1 may not be the direct genetic cause for NOA, and this homozygous mutation might impair spermatogenesis and further lead to the reduced sperm count and abnormal sperm morphology, eventually causing male infertility.
\end{abstract}

\section{Hosted file}

Short report.pdf available at https://authorea.com/users/354197/articles/486129-theheterozygous-mutation-of-c-346-1g-a-in-sohlh1-gene-is-irrelevant-to-nonobstructiveazoospermia

\section{Hosted file}

Table 1.pdf available at https://authorea.com/users/354197/articles/486129-the-heterozygousmutation-of-c-346-1g-a-in-sohlh1-gene-is-irrelevant-to-nonobstructive-azoospermia

\section{Hosted file}

Table 2.pdf available at https://authorea.com/users/354197/articles/486129-the-heterozygousmutation-of-c-346-1g-a-in-sohlh1-gene-is-irrelevant-to-nonobstructive-azoospermia 

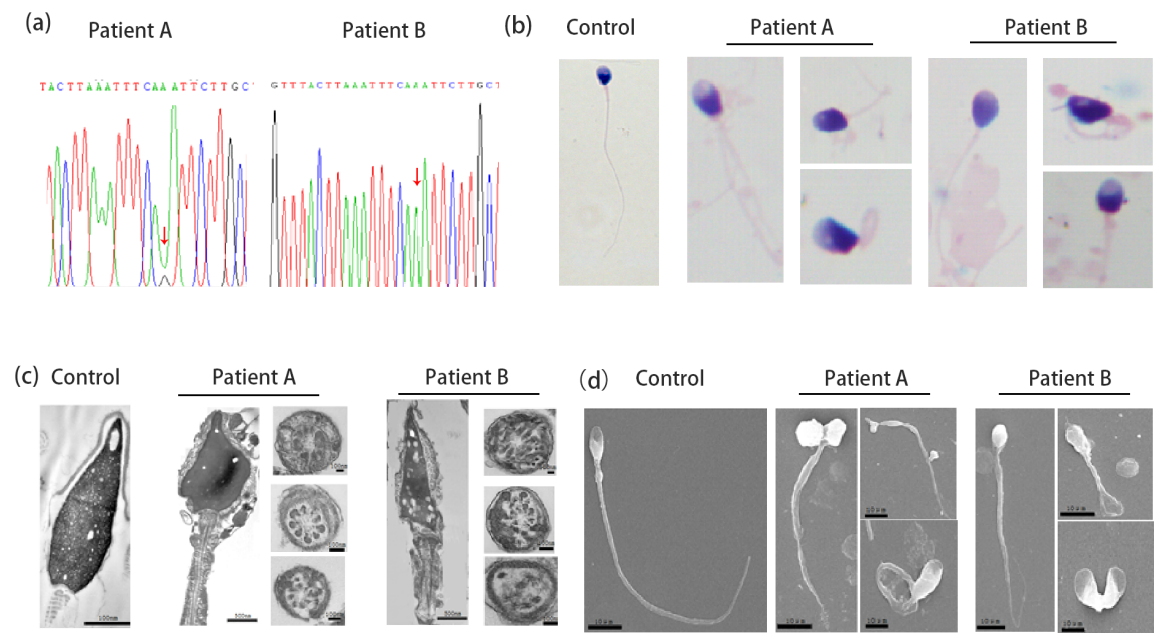